\title{
Holistic behaviour of concrete buildings in fire
}

\section{Bailey}

\section{B. Cole, Buro Happold}

I read with interest the paper on the results of the full-scale fire test carried out in Cardington. It seems clear from the pictures and deflection readings that, although the building did not collapse, the first floor slab was damaged beyond repair. Recently we have been involved in assessing the damage caused by a severe fire on a reinforced concrete building under construction in the Middle East. Although there was extensive spalling of concrete cover, in this case the building remained structurally sound and was repairable.

The building involved is a 30-storey hotel and office tower. At the time of the fire the reinforced concrete frame was nearing completion, and construction work was progressing on the secondary concrete structures above the level of the main roof. The cause of the fire is unknown, but it is possible that it was started by welding operations on the 22nd floor and spread by means of a services shaft to the upper levels of the building (see Fig. 22).

The main fire damage occurred at the top floor level where the timber formwork was still in place beneath the concrete beam and slab construction that will form the flat roof to the tower. The estimated fire load from the timber falsework and plywood shuttering was $82 \mathrm{~kg} / \mathrm{m}^{2}$, considerably higher than that used in the Cardington test. The sides of the building were unclad, and there was a strong northerly wind. The duration of the fire was reported to be approximately $2 \mathrm{~h}$, during which time the timber formwork was entirely consumed by the fire.

Figure 23 shows the soffit of the roof slab after the fire. The damage to the soffit was fairly uniform, with extensive spalling of the concrete cover to the undersides of the slabs and the downstand beams, and some spalling to the sides of the beams. In some areas the outer surface of the reinforcement was exposed, but in all cases the reinforcement remained bonded within the concrete.

Chipping away the concrete (Fig. 24) showed that, in general, the unsound fire-damaged concrete extended to the depth of the main reinforcement (approx. $50 \mathrm{~mm}$ ).

The beam and slab roof construction had been cast in two halves, and the respective sections were 18 days and 13 days old at the time of the fire. Compression tests carried out on numerous cores taken from the limestone aggregate concrete indicated that concrete beyond the fire-damaged zone had adequate compressive strength. Similarly, tension tests on reinforcement specimens taken from the fire zone indicated that there was no significant loss in strength of the hot-rolled steel reinforcement. A level survey of the main beams indicated that there had been very little deflection of the main spans: however, the $4.5 \mathrm{~m}$ cantilever section that extends from one side of the building had deflected beyond calculated values.

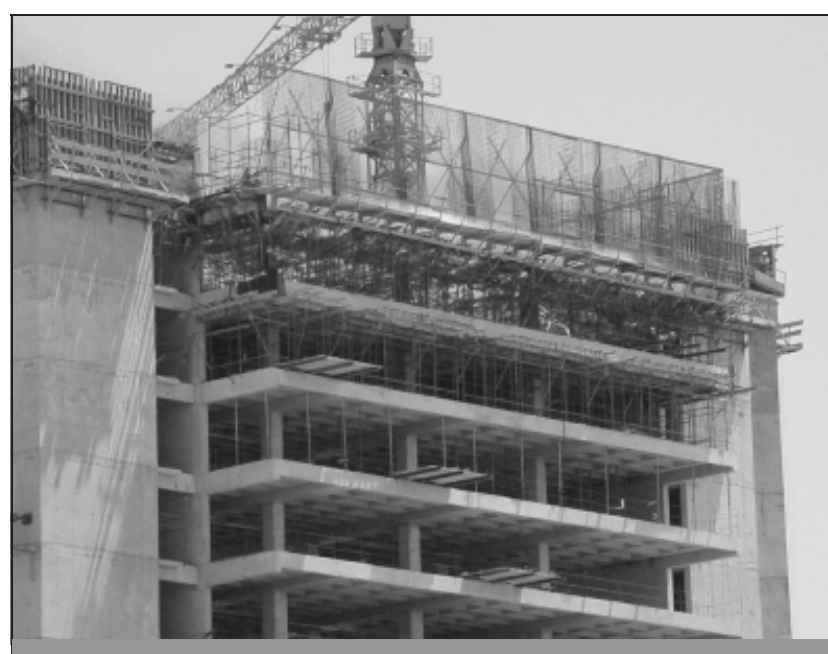

Fig. 22. Timber shuttering beneath roof slab on fire

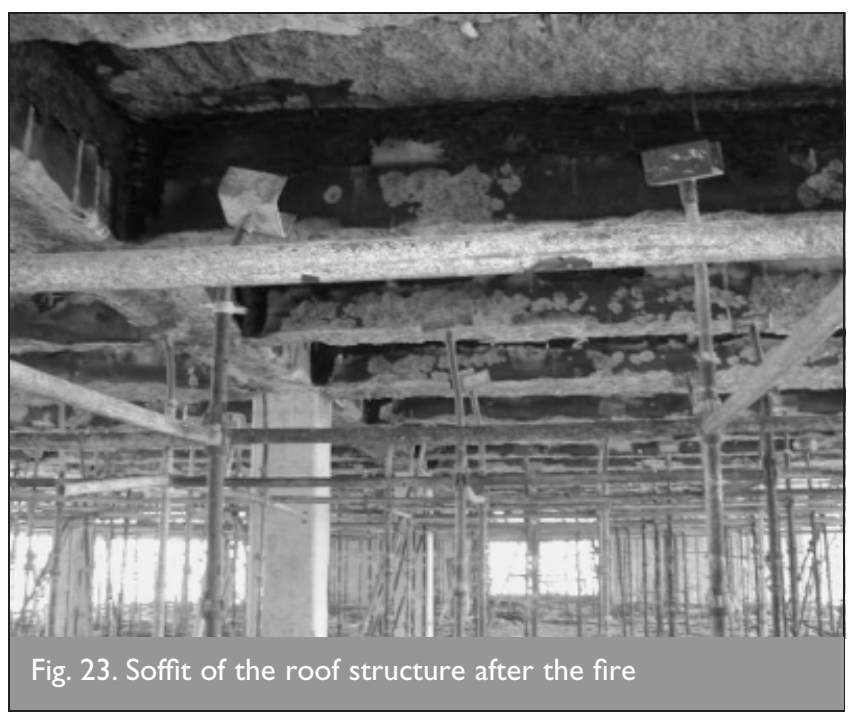




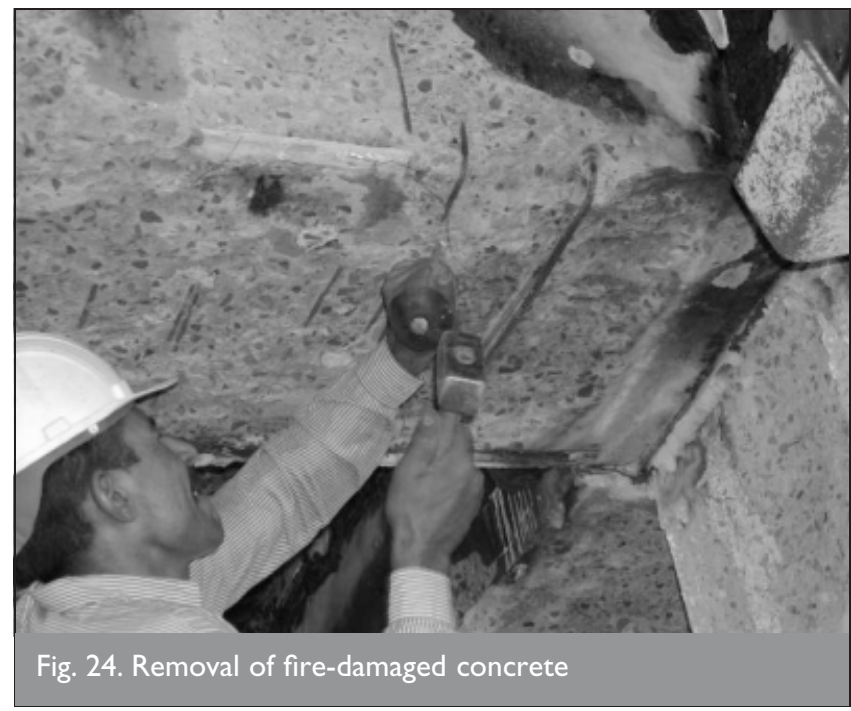

The deflection was not excessive, and was possibly caused by the reduction in beam section due to the fire-damaged concrete on the underside, or could possibly have been due to inaccuracies in construction.

The floor structure below the roof slab is ribbed slab construction, and there was some damage to the infill panels between the ribs. Also, there was extensive spalling to lift shaft and staircase walls and to some internal columns. However, unlike the Cardington test, there were no obvious signs of lateral displacement or damage to the support columns and walls due to lateral expansion of the horizontal structure.

After extensive surveying and testing of the fire-damaged structure, it was decided that the roof and floor structures could be repaired using well-established sprayed concrete techniques. Further structural analysis was also carried out to ensure that the resultant structure would have adequate design factors of safety. Following the completion of the repairs the roof slab will be subjected to a load test.

The principal difference between this structure and the flat slab construction as tested at Cardington was that the shear links in beams retained the tension reinforcement in position throughout the duration of the fire. This prevented the loss of the main tension steel and the resultant excessive deflection of the horizontal structure as witnessed in the Cardington test.

We consider that the experience gained from this investigation demonstrates not only that in-situ reinforced concrete beam and slab construction can safely withstand a severe fire, but also that in certain circumstances this form of reinforced concrete construction can be sufficiently robust to be repairable after the fire has occurred.

\section{Author's reply}

I should like to thank Mr Cole for sharing his valuable experience on the assessment of a fire-damaged concrete building that was under construction at the time of the fire. I should like to add the following comments to Mr Cole's views to further enhance the discussion.

The estimated fire load of $82 \mathrm{~kg} / \mathrm{m}^{2}$ was significantly higher than the $40 \mathrm{~kg} / \mathrm{m}^{2}$ used in the test on the Cardington building. However, the severity of any fire is controlled by the amount of combustible material, ventilation, and the type of linings to compartment walls. The structure under construction had no cladding in place at the time of the fire, resulting in an unrealistic ventilation area, which, coupled with the reported strong northerly wind, would have significantly reduced the severity of the fire.

Apart from the self-weight, the building under construction was not subject to any static design load at the time of the fire. As discussed in the paper, the Cardington building was subjected to a design load of $3 \cdot 25 \mathrm{kN} / \mathrm{m}^{2}$, represented by sandbags distributed over the floor slab, at the time of the fire.

With the structure under construction being 13 and 18 days old at the time of the fire, I would expect the moisture content of the concrete to be significantly higher than the measured moisture content of the concrete in the Cardington building. The higher the moisture content the more susceptible the concrete is to spalling.

The aggregate used on the building under construction was limestone, whereas the slab tested on the Cardington building used an aggregate composed predominantly of flint (chert) material. As discussed in the paper, flint aggregates are more susceptible to spalling.

It seems, from the description given by Mr Cole, that the fire occurred over the whole floor area of the building under construction. The fire test on the Cardington building was carried out in a compartment covering a portion of the floor plate and was surrounded by cold structure on three sides. The cold structure surrounding the compartment fire would have provided restraint to the heated slab, resulting in high in-plane compressive forces within the slab. As discussed in the paper, these high compressive forces would have increased the slab's susceptibility to spalling, but would have also been beneficial in increasing the compressive membrane action in the slab.

The above points are only presented to aid readers who may wish to compare Mr Cole's description of a fire-damaged building (which was under construction at the time of the fire) with the test carried out on the Cardington building. The description presented by Mr Cole is extremely valuable in aiding our overall understanding of buildings in fire, and I should be delighted to hear from any readers who have similar experience of any fire-damaged buildings.

\section{R. Pope, BCSA Technical Consultant}

Given that the fire was much less severe than planned, and it seems that the design fire could have caused collapse, would it have been more likely that the slab would have failed first or that the façade columns would?

What critical conditions might be estimated for these two collapse mechanisms in terms of additional lateral movement of the columns (from $67 \mathrm{~mm}$ max. recorded) or additional slab deflection (from $78 \mathrm{~mm}$ max. recorded)? Can these critical conditions be related to critical fire severities in terms of time and/or maximum temperature? 
The paper stresses that the conclusions of the report relate only to one type of construction, which was a design using a flat slab and high-strength columns. As this differs somewhat from traditional concrete structures in the existing building stock, is the corollary that the history of performance of real concrete buildings in actual fires may not be relied upon to validate the performance in practice of flat slab construction with highstrength columns?

\section{Author's reply}

I should like to thank Dr Pope for his comments, which I shall address in the same order as they were presented.

The paper does not state that the fire was much less severe than planed. As explained in the paper, the fire load was $720 \mathrm{MJ} / \mathrm{m}^{2}$ $\left(40 \mathrm{~kg} / \mathrm{m}^{2}\right)$, which is significantly greater than the $80 \%$ fractile value of $511 \mathrm{MJ} / \mathrm{m}^{2}$ for office buildings given in the Eurocode. As discussed in the paper, various different fire scenarios were considered during the design stage of the test. It is a matter of some debate as to the type of fire that has the most severe effect on concrete buildings. Two types of fire should be considered: a high-temperature, short-duration fire, which may cause spalling of the concrete due to the thermal shock, and a lowtemperature, longer-duration fire, which will result in a greater average temperature through the structure. For the test on the Cardington building it was decided to have a ventilation opening corresponding to $12 \%$ of the floor area, and plasterboard on the compartment walls, to represent a typical office building. The predicted fire scenario is shown in Fig. 5 in the paper and can be classed as a high-temperature, shortduration fire, which as explained above increases the susceptibility of the concrete to spalling. As discussed in the paper, spalling to the underside of the slab occurred during the test, influencing the behaviour of the fire. Spalling of the underside of the slab resulted in the loss of the ceramic blanket around the top of the compartment wall, leading to an increase in ventilation, which resulted in the fire having a slightly higher temperature, and shorter duration, compared with the design fire anticipated. In addition, spalling of the underside of the concrete floor slab resulted in debris falling onto the fire, reducing its temperature. As explained in the paper, reduction of the temperature of the fire by the debris from the spalling of the concrete has also been observed in other fire tests. If spalling did not occur, then it can be argued that the fire could have been more severe in terms of maximum temperature; however, the concrete cover would have remained to the reinforcing steel, making the structure more resistant to the fire. To summarise, it can be concluded that spalling of the underside of a concrete slab can be detrimental, owing to the possibility of exposing the steel reinforcement, but it is also beneficial in that it reduces the maximum temperature of the fire.

The original paper makes no attempt to estimate the critical conditions for the possible modes of failure. The paper does, however, explain modes of behaviour that are ignored in the existing prescriptive approach, as the approach is based on results and observations from small-scale standard fire tests. Further research is required to define the critical conditions for the modes of behaviour identified from the full-scale tests, and to check whether the conservatism embodied in the existing prescriptive approach adequately covers the detrimental modes of behaviour identified in the full-scale test.

The fire design of the existing building stock in the UK has predominantly been based on prescriptive rules derived from small-scale standard fire tests. Over time these rules have been shown to be adequate. However, irrespective of the type of material or structural form adopted, as the design of buildings at the ultimate and serviceability limit states becomes more efficient, resulting in slimmer frames, the inherent safety factors embodied within the existing prescriptive rules may not be sufficient to ensure the required level of safety for fire. The fire test on the Cardington building has begun to address our understanding of how real buildings behave in a fire, allowing the existing prescriptive rules to be checked while also allowing a more robust performance-based design method to be developed. The modes of structural behaviour witnessed on the Cardington building, such as membrane action and pushing out of external columns, are not expected to be unique to flat slab and high-strength column construction, but could occur in most buildings during a fire irrespective of the type of construction adopted. 